KOVALENj:

\title{
EKSTRAKSI GLUKOMANAN DARI UMBI PORANG (Amorphophallus paeniifolius (Dennst.) Nicolson)
}

\section{[Extraction of Tuber Porang Glucomannan (Amorphophallus Paeoniifolius (Dennst.) Nicolson)]}

\author{
Elis Setiawati ${ }^{{ }^{*}}$, Syaiful Bahri ${ }^{1)}$, Abd. Rahman Razak ${ }^{1)}$ \\ 1 Jurusan Kimia Fakultas MIPA, Universitas Tadulako \\ Jl. Soekarno Hatta Km.9, Kampus Bumi Tadulako Tondo Palu, Telp. 0451- 422611 \\ *)Coresponding author: eliswati.mipa@gmail.com
}

Diterima 22 Juli 2017, Disetujui 4 September 2017

\begin{abstract}
This study aims to determine the temperature and the ratio of tuber flour porang using isopropyl alcohol precipitator in producing glucomannan extract with the highest yield. The study was designed using completely randomized design (CRD), which consists of two factors: the temperature of the extraction consists of seven levels $\left(45,55,65,75,85,95\right.$, and $\left.105{ }^{\circ} \mathrm{C}\right)$ and the ratio of tuber flour porang by precipitating isopropyl alcohol consists of 5 level $(1: 7,1: 10,1: 13,1: 16$, and 1:19 (w/v). each done in duplicate. parameters measured were yield characteristics glucomannan and the results showed that the extraction of the best glucomannan obtained at a temperature of $95{ }^{\circ} \mathrm{C}$ with a yield of $41.614 \%$. the ratio of starch tuber porang best isopropyl alcohol is $1: 19(\mathrm{w} / \mathrm{v})$ with a yield of $45.167 \%$ glucomannan. Test characteristics of glucomannan gained $6.6 \%$ moisture content, the ash content of $0.8 \%$, and a molecular weight of $0.726 \times 10^{4} \mathrm{~g} / \mathrm{mol}$.
\end{abstract}

Keywords : porang tuber flour, shaking temperature, glucomannan.

\begin{abstract}
ABSTRAK
Penelitian ini bertujuan untuk mengetahui suhu dan rasio tepung umbi porang menggunakan pengendap isopropil alkohol dalam menghasilkan ekstrak glukomanan dengan rendemen tertinggi. Penelitian dirancang menggunakan Rancangan Acak Lengkap (RAL) yang terdiri atas 2 faktor yaitu suhu ekstraksi terdiri atas 7 taraf $\left(45,55,65,75,85,95\right.$, dan $\left.105^{\circ} \mathrm{C}\right)$ dan rasio tepung umbi porang dengan pengendap isopropil alkohol terdiri dari 5 taraf $(1: 7,1: 10,1: 13,1: 16$, dan 1:19 (b/v), masingmasing dilakukan secara duplo. Parameter yang diamati adalah rendemen glukomanan dan karakteristiknya hasil penelitian menunjukkan bahwa ekstraksi glukomanan terbaik diperoleh pada suhu $95^{\circ} \mathrm{C}$ dengan rendemen $41,614 \%$. Rasio tepung umbi porang isopropil alkohol terbaik yaitu 1:19 (b/v) dengan rendemen glukomanan $45,167 \%$. Uji karakteristik terhadap glukomanan diperoleh kadar air $6,6 \%$, kadar abu $0,8 \%$, dan berat molekul $0.726 \times 10^{4} \mathrm{~g} / \mathrm{mol}$.
\end{abstract}

Kata kunci: tepung umbi porang, suhu pengocokan, glukomanan. 


\section{LATAR BELAKANG}

Umbi porang Amorphophalus paeniifolius (Dennst) Nicolson merupakan salah satu sepesies famili Araceae yang dimanfaatkan untuk memenuhi kebutuhan hidup masyarakat Indonesia diantaranya sebagai bahan makanan, obat-obatan dan tanaman hias. Pemanfaatan tanaman Araceae sebagai bahan makanan dan obat-obatan dapat berasal dari daun, batang atau umbinya Heyne, K (1987) dalam (Ekowati, dkk. 2015). Umbi porang dapat dikonsumsi langsung seperti suweg Amorphophallus campanulatus, $A$. variabilis dan talas Colocasia esculenta. Meskipun demikian, umbi porang yang tidak dapat dikonsumsi langsung seperti spesies Amorphophalus paeniifolius (Dennst) Nicolson.

Tanaman jenis Umbi Porang Amorphophallus muelleri Blume banyak ditemukan tumbuh di hutan-hutan pulau Jawa. Di Negara Jepang umbi ini dikenal dengan "Jawa Mukago Konyaku". Umbi porang banyak dibudidayakan di daerah Jawa Timur oleh Kesatuan Pemangkuan Hutan (KPH) Saradan di Desa Klangon, Kecamatan Saradan Kabupaten Madiun. Produksi umbi porang pada tahun 2005 di Desa Klangon mencapai 5.535 ton. Dinas Pertanian Tanaman Pangan dan Hortikultura Kabupaten Madiun mengambbarkan bahwa pada tahun 2007, produksi umbi porang di Kabupaten Madiun mencapai 7.314 ton dan meningkat menjadi 8.803 ton pada tahun 2009 (Krysanti, 2014).
Sulawesi tengah merupakan daerah subtropis yang kaya akan kenanekaragaman hayati, misalnya Umbi porang Amorphophalus paeniifolius (Dennst) Nicolson tenggah banyak tumbuh di Desa Wombo, Kecamatan Tanantovea. Tanaman ini tumbuh liar di daerah perbukitan dan belum dimanfaatkan oleh masyarakat sebagai sumber makanan. Hal ini desebabkan masyarakat menganggap sebagai tanaman gulma. Kurangnya pemanfaatan umbi porang (Amorphophalus paeniifolius (Dennst) Nicolson) sebagai bahan makanan karena mengandung banyak kalium oksalat yang menyebabkan rasa gatal (Prayudyaningsih dkk, 2015).

Hasil penelitian yang dilakukan oleh beberapa peneliti terhadap glukomanan dari berbagai jenis umbi porang, menunjukan hasil yang berbeda baik dari sisi rendemen glukomanan maupun suhu yang digunakan untuk ekstraksi. Harijati, dkk (2013) memperoleh rendemen glukomanan sebesar $63,1 \%$, dengan suhu ekstraksi $55^{\circ} \mathrm{C}$ pada umbi porang jenis Amorphophalus mulleri Blume. Nugraheni (2015) melaporkan bahwa rendemen glukomanan pada umbi porang jenis Amorphophallus Konjac Koch. adalah $15,49 \%$ dengan suhu ekstraksi 75-78 9 C. Sumarwoto (2007) melaporkan rendemen glukomanan dari umbi porang jenis Amorphophalus Muller Blume rendemen glukomanannya adalah $64,22 \%$ dengan suhu ekstraksi $45 \stackrel{\circ}{\circ}$. Berdasarkan hal tersebut terlihat bahwa rendemen 
glukomanan pada setiap jenis umbi porang berbeda satu dengan yang lainnya untuk itu juga suhu ekstraksi yang diperlukan, hal ini menunjukan bahwa rendemen glukomanan yang terdapat dalam umbi porang berpengaruh pada suhu ekstraksi.

Berdasarkan hal di atas peneliti ingin melakukan penelitian terhadap umbi porang jenis Amorphophalus paeniifolius (Dennst) Nicolson untuk mengetahui kondisi ekstraksi yang diperlukan, hal ini dilakukan karena jenis umbi porang tersebut belum diketahui berapa suhu ekstraksi dan perbandingan rasio antisolvent isopropil alkohol yang digunakan.

\section{METODE PENELITIAN}

\section{Bahan dan Peralatan}

Bahan yang akan digunakan pada penelitian ini adalah umbi porang. Bahanbahan lainnya: aquadest, isopropil alkohol 95\%, etanol 95\% dan $\mathrm{KBr}$.

Peralatan yang akan digunakan pada penelitian adalah : blender, gelas kimia, hot platemerk (WiseStir MSH 20-D), homogenizer speed 0-3000 rpm,kertas saring, oven merk (memmert), neraca analitik merk (Adventure TM Ohaus), desikator, cawan porselen, tanur merk (Nabertherm gmBh), spektrofotometer FTIR, sentrifugasi, viscometer ostwald dan alat-alat gelas lainnya.

\section{Rancangan Penelitian}

Penelitian ini menggunakan Rancangan Acak Lengkap (RAL) dengan variabel bebas suhu ekstraksi dan rasio tepung umbi porang terhadap anti-solvent isopropil alkohol 95\% dengan variabel terikat rendemen glukomanan. Variabel suhu pengocokan terdiri dari 7 taraf, yaitu Suhu $45^{\circ} \mathrm{C}, 55^{\circ} \mathrm{C}, 65^{\circ} \mathrm{C}, 75^{\circ} \mathrm{C}, 85^{\circ} \mathrm{C}, 95$ ${ }^{\circ} \mathrm{C}$ dan $105^{\circ} \mathrm{C}$, sedangkan variabel rasio tepung umbi porang : anti-solvent isopropil alkohol 95\% terdiri dari 5 taraf, yaitu 1:7, $1: 10, \quad 1: 13, \quad 1: 16$ dan 1:19 (b/v) dan masing-masing diulang dua kali.

\section{Prosedur Penelitian}

\section{Preparasi sampel}

Umbi porang di pisahkan dari batang dan kulitnnya. Umbi dicuci dengan air mengalir hingga bersih, di iris-iris dengan tebal 0,7-1 cm. Irisan-irisan umbi kemudian di keringkan dibawah sinar matahari sampai kondisi keripik mudah dipatahkan (kadar airnya $\pm 11 \%$ ). Irisan tipis umbi porang diblender dan diayak dengan ayakan 60 mesh hingga di peroleh tepung umbi porang.

\section{Ekstraksi glukomanan}

Tepung umbi porang ditimbang 50 g, kemudian dimasukkan sedikit demi sedikit ke dalam gelas kimia yang berisi aquadest dengan perbandingan 1:30 (b/v) sambil diaduk-aduk dengan menggunakan homogenizer dengan kecepatan 700 rpm. Campuran diaduk dengan konstan pada suhu $45^{\circ} \mathrm{C}, 55^{\circ} \mathrm{C}, 65^{\circ} \mathrm{C}, 75^{\circ} \mathrm{C}, 85^{\circ} \mathrm{C}, 95$ $\stackrel{\circ}{ } \mathrm{C}$ dan $105^{\circ} \mathrm{C}$ selama 120 menit. Campuran yang terbentuk disentrifugasi pada kecepatan $3000 \mathrm{rpm}$ selama 15 menit untuk mendapatkan filtratnya. Filtrat dipekatkan hingga setengah volume awal, 
ke dalam filtrat ditambahkan isopropil alkohol $95 \%$ dengan perbandingan 1:7, $1: 10,1: 13,1: 16$ dan 1:19 (b/v) (massa tepung dalam larutan isopropil alcohol) sedikit demi sedikit sambil diaduk-aduk (Ohtsuki, 1968). Glukomanan yang mengendap dipisahkan dengan cara penyaringan menggunakan kertas saring. Endapan glukomanan dicuci dengan etanol $95 \%$ dan dikeringkan dalam oven pada suhu $40{ }^{\circ} \mathrm{C}$ selama 24 jam. Glukomanan kering selanjutnya ditimbang.

\section{HASIL DAN PEMBAHASAN}

\section{Rendemen Glukomanan Umbi Porang Pada Berbagai Suhu}

Glukomanan merupakan komponen karbohidrat yang paling banyak dalam tepung umbi porang. Salah satu faktor yang mempengaruhi rendemen hasil ekstraksi glukomanan adalah suhu. Hasil yang diperoleh (Gambar 1) menunjukkan bahwa rendemen yang dihasilkan meningkat dari suhu $45{ }^{\circ} \mathrm{C}$ sedangkan pada suhu $105^{\circ} \mathrm{C}$ mengalami penurunan.

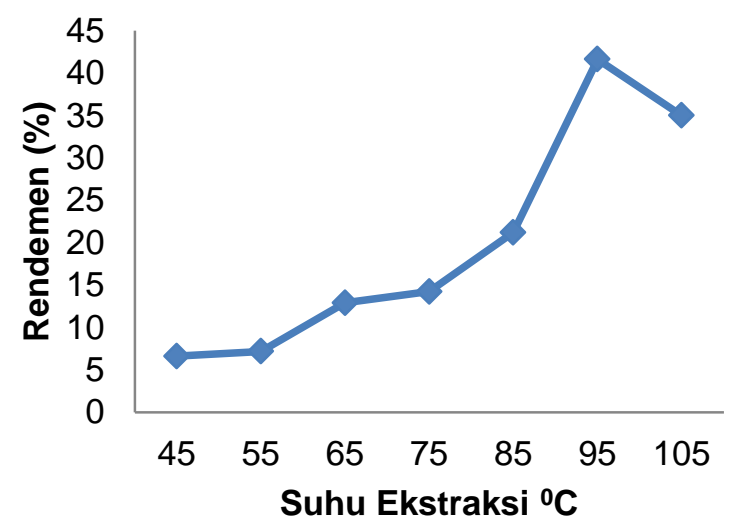

Gambar 1. Grafik hubungan suhu pengocokan terhadap rendemen glukomanan
Gambar 1 menunjukan bahwa rendemen glukomanan umbi porang mengalami peningkatan dari suhu pengadukan 45 으 sampai $95^{\circ} \mathrm{C}$. Rendemen glukomanan tertinggi adalah $41,61 \%$ diperoleh pada penggunaan suhu $95{ }^{\circ} \mathrm{C}$, sedangkan pada suhu $105{ }^{\circ} \mathrm{C}$ didapatkan rendemen sebesar 34,98\%. Pada suhu $105^{\circ} \mathrm{C}$ terjadi penurunan. Penurunan kadar glukomanan ini disebabkan oleh glukomanan tersebut mengalami proses gelatinisasi, sehingga menjadi rusak. Pada suhu tinggi glukomanan akan terurai menjadi molekulmolekul yang lebih kecil atau mengalami hidrolisis (Tatirat dkk, 2011).

Rendemen glukomanan terhadap Rasio Tepung Umbi Porang dengan Isopropil Alkohol 95\%

Untuk mengetahui rasio isopropil alkohol $95 \%$ terhadap tepung umbi porang yang menghasilkan kadar glukomannan yang tinggi, diterapkan lima tingkatan rasio masing-masing 1:7, 1:10, $1: 13,1: 16$ dan $1: 19(b / v)$. Hasil yang diperoleh menunjukkan semakin banyak penggunaan isopropil alkohol $95 \%$ atau semakin meningkat rasio isopropil alkohol 95\% terhadap tepung umbi porang semakin tinggi pula kadar glukomanan yang dihasilkan. Kadar glukomannan tertinggi (45,167\%) ditemukan pada penggunaan rasio isopropil alkohol $98 \%$ terhadap tepung umbi porang 1:19 atas dasar $b / v$, sedangkan kadar glukomannan terendah $(24,48 \%)$ terdapat pada penggunaan rasio isopropil alkohol $98 \%$ 
terhadap tepung umbi porang $1: 7$ atas dasar $\mathrm{b} / \mathrm{v}$.

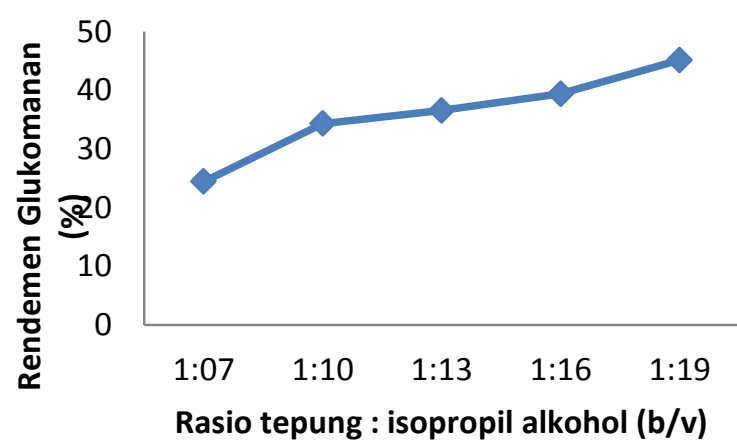

Gambar 2. Grafik hubungan rasio tepung umbi porang dengan isopropil alkohol 95\% (b/v) terhadap rendemen glukomanan

Pada Gambar 2 memperlihatkan bahwa rendemen glukomanan tepung umbi porang berkorelasi positif bertambahnya volume anti-solvent isopropil alkohol 95\% yang ditambahkan. Hal tersebut disebabkan karena semakin banyak anti-solvent yang ditambahkan pada pelarut maka semakin banyak air yang akan ditarik oleh anti-solvet tersebut dari filtrat yang mengakibatkan glukomanan yang memiliki bobot molekul lebih besar akan mengendap.

\section{Karakteristik Glukomanan}

\section{Kadar Air}

Berdasarkan hasil yang di dapatkan pada pengukuran kadar air glukomanan adalah 6,6 \%. Kadar air hasil analisis tepung umbi porang cukup baik karena telah memenuhi standar mutu yang ditetapkan oleh Asosiasi Konyaku Jepang (1976) yaitu kurang dari 13\%.
Menurut Fardiaz (1989), batas kadar air minimum dimana mikroorganisme masih dapat tumbuh adalah 14-15\%. Kadar air yang terlalu tinggi dapat menyebabkan penurunan mutu produk yang dihasilkan. Umbi porang (Amorphophalus paeniifolius (Dennst) Nulcolson) lebih baik digunakan untuk bahan pangan karena kadar air yang di peroleh lebih kecil. Kadar air dalam bahan pangan sangat mempengaruhi kualitas dan daya simpan dari bahan pangan tersebut. Kadar air bahan pangan yang tinggi dapat menyebabkan beberapa kerusakan antara lain pertumbuhan mikroba, reaksi pencoklatan dan hidrolisis lemak (De Man, 1997).

\section{Kadar Abu}

Berdasarkan hasil analisis kadar abu yang didapatkan pada tepung glukomanan umbi porang, didapatkan kadar abu sebesar 0,8\%. Kadar abu pada tepung glukomanan umbi porang telah memenuhi standar mutu yang ditetapkan oleh Asosiasi Konyaku Jepang (1976) yaitu kurang dari $4,5 \%$.

\section{Berat Molekul}

Penentuan berat molekul glukomanan bertujuan untuk penggunaannya dalam industri baik makanan maupun yang lainnya. Polimer yang memiliki berat molekul besar diaplikasikan untuk bahan tambahan makanan. Berdasarkan hasil penelitian diperoleh berat molekul glukomanan umbi porang adalah $0,726 \times 10^{4} \mathrm{~g} / \mathrm{mol}$. 
4. Gugus Fungsional Glukomanan

Identifikasi gugus fungsional glukomanan dilakukan dengan menggunakan spektrofotometer infra merah. Hasil yang diperoleh terlihat pada Gambar 3.

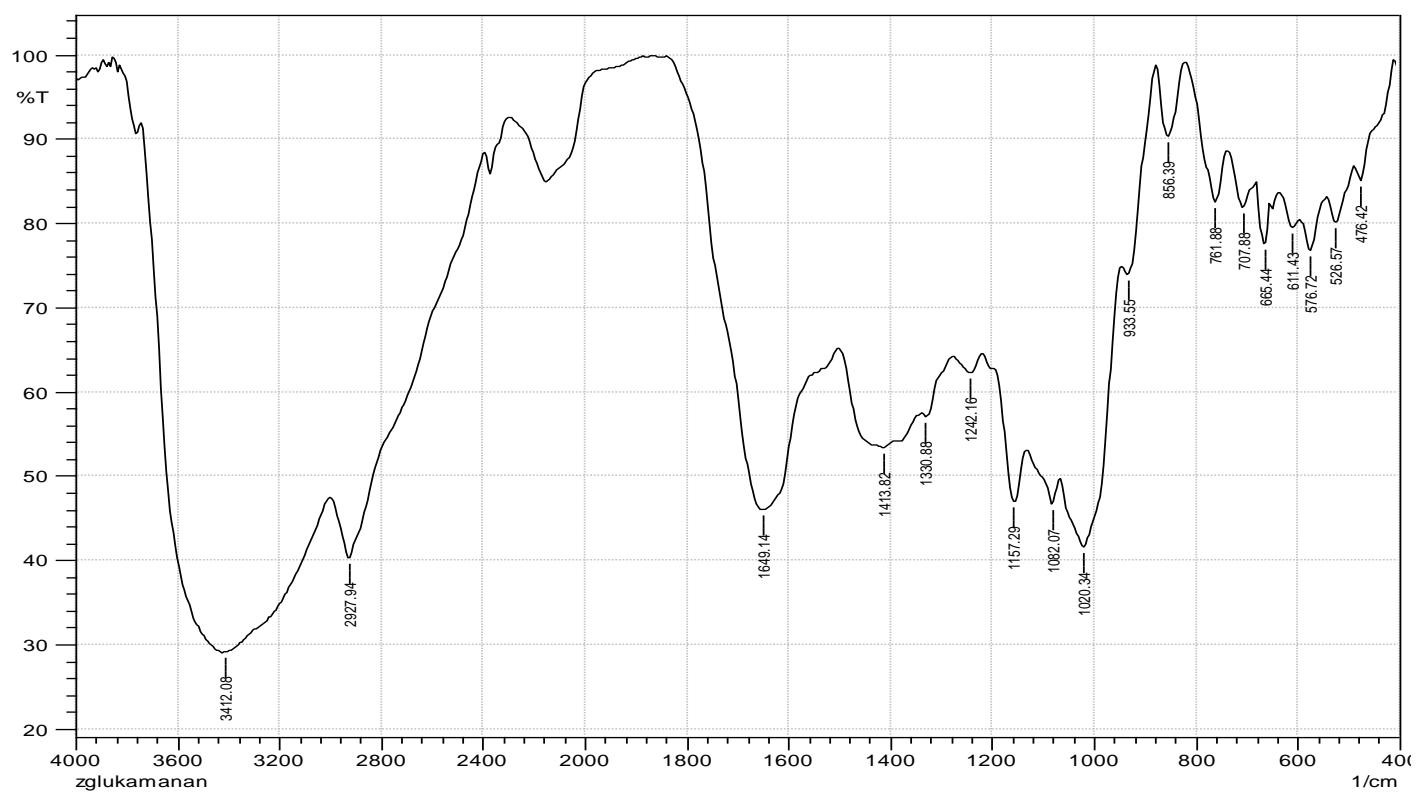

Gambar 3. Spektrum FTIR Glukomanan umbi porang

Pada Gambar 3 spektrum infra merah glukomanan, serapan vibrasi ulur gugus $-\mathrm{OH}$ terdapat pada bilangan gelombang $3412,08 \mathrm{~cm}^{-1}$. Serapan pada bilangan gelombang 2.927,94 $\mathrm{cm}^{-1}$ menunjukkan vibrasi ulur gugus $\mathrm{C}-\mathrm{H}$ alkana $\left(-\mathrm{CH}_{3}\right.$ atau $\left.-\mathrm{CH}_{2}-\right)$. Pita serapan pada bilangan gelombang $1.649,14 \mathrm{~cm}^{-1}$ menunjukkan adanya gugus $\mathrm{C}=\mathrm{O}$ (karbonil). Pita serapan pada bilangan gelombang $1.020 .34 \mathrm{~cm}^{-1}$ menunjukkan adanya gugus fungsi C-O-C (ikatan glikosidik) dan pada pita serapan pada bilangan gelombang 856,39 $\mathrm{cm}^{-1}$ menunjukkan vibrasi tekukan gugus $-\mathrm{CH}$. gugus manosa dan glukosa terlihat melalui kenampakan pita pada $853,39 \mathrm{~cm}^{-}$ ${ }^{1}$ yang berkaitan dengan vibrasi tekukan gugus $-\mathrm{CH}$.

\section{Kromatografi Lapis Tipis}

Kromatografi merupakan pemisahan diferensial komponen sampel diantara fase gerak dan fase diam. Kromatografi Lapis Tipis (KLT) dilakukan bertujuan untuk mengetahui pola kromatogram yang dihasilkan dari pemisahan senyawa yang terdapat pada sampel. Eluen yang digunakan adalah Methanol $95 \%$. Menurut (Chairul, 2006), glukomanan merupakan senyawa yang bersifat semi polar sehingga untuk pemisahan menggunakan kromatografi lapis tipis dapat menggunakan fase gerak berupa methanol 95\%. Yang telah dijenuhkan terlebih dahulu, untuk mengidentifikasi senyawa yang ada pada glukomanan hasil ekstraksi maka digunakan eluen methanol, sehingga terlihat ekstraksi tepung umbi porang menggunakan 
pengendap isopropil alkohol diperoleh Senyawa glukomannan dengan nilai RF sampel glukomannan $(0,66)$ dan nilai $R F$ glukomannan $70 \%(0,66)$ bisa dikatan hasil yang di peroleh telah sesuai dengan pembanding glukomnan $70 \%$.

\section{KESIMPULAN}

Berdasarkan hasil penelitian dapat disimpulkan bahwa suhu ekstraksi yang terbaik didapatkan pada suhu $95{ }^{\circ} \mathrm{C}$ dengan rendemen glukomanan yang dihasilkan 41,614\%. Rasio terbaik yang didapatkan adalah 1:19 (1 bagian berat tepung umbi porang dan 19 bagian isopropil alkohol) dengan rendemen glukomanan yang dihasilkan adalah 45,167\%. Hasil karakteristik glukomanan yang diperoleh antara lain kadar air 6,6\%, kadar abu $0,8 \%$, dan berat molekul 0,726 $\times 10^{4} \mathrm{~g} / \mathrm{mol}$.

Perlu dilakukan ujilebih lanjut untuk rasio anti-solven isopropil alkohol untuk mendapatkan nilai maksimum dan karakterisasi lebih lanjut seperti kadar pati, kadar serat, derajat putih dan kekuatan gel. Serta perlu dilakukan pemurnian glukomanan dari umbi porang.

\section{UCAPAN TERIMAKASIH}

Terimakasih kepada pranata laboratorium jurusan kimia FMIPA Universitas Tadulako yang telah membantu dalam pelaksanaan penelitian.

\section{DAFTAR PUSTAKA}

Assosiasi Konyaku Jepang. 1976. Penetapan Standarisasi Tepung
Glukomanan Murni lles-iles dan Halhal Penting dalam Pelaksanaannya. Assosiasi Konyaku Jepang. Dewan Pengurus Konyaku Tingkat Propinsi.

Nugraheni, B 2015. Analisis Kimia, Makronutrien Dan Kadar Glukomannan Pada Tepung Umbi Porang (Amorphophallus Konjac K. Koch). Setelah Dihilangkan Kalsium Oksalatnya Menggunakan $\mathrm{NaCl} 10$ \%. Jurnal Teknologi Pangan dan Hasil Pertanian. 9 (1): 16-23

Chairul, 2006. Isolasiglukomanan Daridua Jenis Araceae: Talas \{Colocasia esculenta (L.) Schott Dan Iles-lles (Amorphophallus campanulatus Blumei) [Isolation Of Glucomannan From Two Species Of Araceae: Talas \{Colocasia esculenta (L.). Schott $\quad$ And lles-lles \{Amorphophallus campanulatus Blumei)]. Berita Biologi 8(3):171178.

De Man, J.M. 1997. Kimia Makanan. Bandung: Penerbit ITB.

Ekowati G, Yanuwiadi B, Azrianingsih R, 2015. Sumber Glukomanan Dari Edible Araceae $\mathrm{Di}$ Jawa Timur. JPAL. 6, (1): hal 32-41

Fardiaz, S. 1989. Mikrobiologi Pangan I. PAU Pangan Gizi. Bogor: Institut Pertanian Bogor.

Harijati, Nunung, Indriyani, Serafinah., Mastuti, dan Retno. 2013. Pengaruh temperatur ekstraksi terhadap sifat fisikokimia glukomanan asal Amorphophallus muelleri Blume. Jurnal Natural B, 2 (2): 128-133.

Krysanti, A., dan Widjanarko, S.B. (2014). Toksisitas Subakut Tepung Glukomanan (A. Miller Blume) Terhadap S GOT Dan Natrium Tikus Wistar Secara In Vivo. Jurnal Pangan Dan Agroindustri. 2(1):1-7.

Ohtsuki, T. 1968. Studies on reserve carbohydrates of flour Amorphophallus species, with special reference to manan. Botanical Magazine Tokyo (81): 119 $-126$. 
Prayudyaningsih et, al., 2015. Keragaman Tanaman Umbi Dan Fungsi Mikoriza Arbuskula (Fma) Di Bawah Tegakan Hutan Rakyat Sulawesi Selatan. Jurnal Penelitian Kehutanan Wallacea. 4 (1): 81-92.

Sumarwoto. $2005.2 \quad$ lles-lles (Amorphophallus muller Blume) Deskripsi Dan Sifat-Sifat Lainnya. Biodiversitas. 6 (3):185-190.

Tatirat, O., Charoenrein, S. 2011. Physicochemical properties of konjac glucomannan extracted from konjac flour by a simple centrifugation process. LWT - Food Science and Technology. 44 (10): 2059-2063. 